\title{
High-resolution sensing for precision agriculture: from Earth- observing satellites to unmanned aerial vehicles
}

\author{
Matthew F. McCabe*a, Rasmus Houborg ${ }^{\mathrm{a}}$, Arko Lucieer ${ }^{\mathrm{b}}$ \\ ${ }^{a}$ King Abdullah University of Science and Technology, Water Desalination and Reuse Center, \\ Division of Biological and Environmental Sciences and Engineering, Saudi Arabia. \\ ${ }^{\mathrm{b} S u r v e y i n g}$ and Spatial Sciences Group, School of Land and Food, University of Tasmania, Australia
}

\begin{abstract}
With global population projected to approach 9 billion by 2050, it has been estimated that a $40 \%$ increase in cereal production will be required to satisfy the worlds growing nutritional demands. Any such increases in agricultural productivity are likely to occur within a system that has limited room for growth and in a world with a climate that is different from that of today. Fundamental to achieving food and water security, is the capacity to monitor the health and condition of agricultural systems. While space-agency based satellites have provided the backbone for earth observation over the last few decades, many developments in the field of high-resolution earth observation have been advanced by the commercial sector. These advances relate not just to technological developments in the use of unmanned aerial vehicles (UAVs), but also the advent of nano-satellite constellations that offer a radical shift in the way earth observations are now being retrieved. Such technologies present opportunities for improving our description of the water, energy and carbon cycles. Efforts towards developing new observational techniques and interpretative frameworks are required to provide the tools and information needed to improve the management and security of agricultural and related sectors. These developments are one of the surest ways to better manage, protect and preserve national food and water resources. Here we review the capabilities of recently deployed satellite systems and UAVs and examine their potential for application in precision agriculture.
\end{abstract}

Keywords: Precision agriculture, UAV, Satellite, Remote sensing, Vegetation health, Crop height, NDVI

\section{INTRODUCTION}

Current global food production levels will need to double in order to match projected population growth by $2050^{1}$. However, the corresponding increases in water that will be needed to drive this production are often overlooked. While an estimated water increase of $20 \%$ to meet this growth in food demand may seem reasonable, the value could be much higher if the agricultural advancements required to deliver this food target are not met. Furthermore, such global projections do not always consider the regional scale implications that climate change may have, nor the water resources over-exploitation that occurs in many locations. The latter is a particular concern for many regions, but especially the Middle East, which has witnessed a dramatic increase in their agricultural sectors over the last few decades. Motivated largely by food security concerns, this increased production has often come at the cost of an unsustainable use of groundwater resources. At the global scale, the proportion of water used in agriculture has been estimates at more than $70 \%^{2}$. In arid regions such as Saudi Arabia, this value is much higher, with close to nine out of every ten liters of water consumed in agricultural production derived from already stressed groundwater systems ${ }^{3}$. It is obvious that efforts to increase food production in such regions need to consider parallel responses to crop water use ${ }^{4}$ and health to ensure the continued sustainability of already vulnerable water resources and the effective management of agricultural systems.

Precision agriculture represents one approach that is motivated with this goal in mind. Through detailed observation and monitoring of agricultural systems, precision farming essentially aims to optimize the use of inputs (water, nutrients, chemicals) in order to maximize outputs (the crop yield). To do this demands that a wide range of information be collected in a dynamic manner, mapping both the spatial and temporal change in variables such as soil moisture ${ }^{5}$, evaporation ${ }^{6}$, vegetation indices ${ }^{7}$, trace elements and other metrics of crop development and health ${ }^{8}$. Given the scale of agricultural operations, the only feasible option to monitor such systems on a regional scale is via remote sensing ${ }^{9}$. While in-situ data and related on-farm collections (i.e. tractor or irrigation mounted sensors) are critically important to ensuring the fidelity of observations, their limited spatial support scale (and capital cost) currently constrain the development of a fully

Remote Sensing for Agriculture, Ecosystems, and Hydrology XVIII, edited by

Christopher M. U. Neale, Antonino Maltese, Proc. of SPIE Vol. 9998, 999811

(C) 2016 SPIE - CCC code: $0277-786 X / 16 / \$ 18 \cdot$ doi: $10.1117 / 12.2241289$ 
distributed sensor network that is needed to monitor both inter- and intra-field variations for precision agricultural purposes. Remote sensing approaches provide the spatial detail required to provide distributed monitoring of large scale agricultural systems in a way that in-situ data cannot $^{10}$.

However, remote sensing systems have often lacked the required spatio-temporal resolution to be effective in driving precision agricultural applications ${ }^{11}$. In many instances, derived variables that were available at suitable spatial resolutions (prescribed herein as less than $50 \mathrm{~m}$ ), were usually only available at relatively poor temporal resolutions. For example, Landsat platforms, one of the most widely used earth observing (E-O) satellites, provide spectral resolutions on the order of $30 \mathrm{~m}$ in the visible and near-infrared, but have a repeat interval approaching 17 days. For many agricultural applications, this frequency is unsuitable, especially when considering issues of cloud cover that inevitably increase the time between clear-sky overpasses. Even the spatial scale may not be appropriate for determining within field variability, especially at the relatively coarse $90 \mathrm{~m}$ resolution of the available thermal band that is used to estimate surface temperature ${ }^{12}$. The launch of the European Space Agencies (ESA) Sentinel-2 platform provides a significant improvement in revisit time and multi-spectral capability and is set to become a key tool in precision agricultural applications. In parallel with systems launched by government space agencies, a number of commercial earth-observing companies provide imagery that are relevant to, or specifically designed for, precision agricultural applications. The SPOT (Satellite Pour l'Observation de la Terre) platform is an early example of such an approach (albeit in collaboration with government research organizations), as is the five-satellite constellation RapidEye system. Within the last few years, a number of other geospatial focused companies have launched their own platforms, either as data providers (e.g. Planet https://www.planet.com/) or information providers (e.g. Google's Terra Bella https://terrabella.google.com/). These and related companies are changing the landscape of traditional earth observation.

While satellite based observation have undoubtedly driven numerous information-based advances in farm management and practice, it is the advent of unmanned aerial vehicles that presents as a potential game-changer in precision farming applications. With both fixed with and copter based platforms, data at unprecedented resolutions (i.e. $\mathrm{cm}$ scale) can be routinely captured at the field level on an as needed basis. Indeed, the leaf-scale retrieval potential of these platforms presents unique challenges in terms of process understanding (i.e. observations leading model capability) as well as computational and processing issues (i.e. interpreting and handling the data). In some areas of analysis, the technology is ahead of the science. Regardless of these issues, the potential of UAVs to provide information relevant to precision agricultural applications is obvious. However, there are still some challenges to overcome in fully realizing this potential. The purpose of this paper is to present a brief overview of some of these, focusing on both UAVs and also satellite observations, as well as to showcase the available technology and retrieval opportunity through examples of recent applications.

\section{REMOTE OBSERVATION PLATFORMS FOR PRECISION AGRICULTURE}

\subsection{Space-agency based satellite systems}

Over the last few decades, there has been considerable effort directed towards the estimation of a range of terrestrial variables, such as land cover changes ${ }^{13}$, land surface fluxes ${ }^{6,14}$ and vegetation retrievals ${ }^{15}$ via an array of government agency led space satellite programs. These include sensors and satellites that have been launched by the National Aeronautics and Space Administration (NASA), the European Space Agency (ESA), Japan's Aerospace Exploration Agency (JAXA) and more recently the Chinese National Space Agency (CNSA). From an agricultural monitoring perspective, foremost amongst these efforts has been the long term Landsat data continuity mission ${ }^{16}$, which has provided an unprecedented record of terrestrial change and related information that is of interest to the precision agriculture community. However, while such agency based missions have provided the backbone of earth observation data across a range of disciplines and fields of study, their application to core precision agricultural purposes has been constrained by considerations related to spatial and temporal resolution. In the case of Landsat, with orbital considerations, optics and data-transfer limitations, a spatial resolution on the order of several tens of meters was coupled with a temporal resolution of greater than two weeks. Both of these retrieval characteristics are sub-optimal to drive advances in precision agriculture, where details on within field to plant-scale variability, together with daily (or even sub-daily) repeat rates, are desired. In order to keep track of crop health and development in a dynamic manner, higher spatial and temporal resolutions are needed. Still, Landsat data have proved to be useful in offering a snap-shot of agricultural systems, providing the information necessary to inform decision support systems and needed geospatial datasets ${ }^{17}$. 
The evolution of the Landsat mission has been met by ESA's Sentinel 2 program ${ }^{18}$. The launch of Sentinel 2A in June 2015 provided a significant advance in technological capacity as well as retrieval characteristics. With 13 spectral bands spanning the visible, near infra-red and short wave infra-red region, the satellite also offers a range of spatial resolutions from 10 to 60 meters (see https://earth.esa.int/web/sentinel/missions/sentinel-2/instrument-payload/resolution-and-swath). As important as the advances in spatial and spectral properties that this system offers, so too is the increase in temporal resolution. For example, Sentinel-2A has a repeat cycle of 10 days (at the equator): but with the launch of Sentinel-2B (scheduled for 2017), this will be reduced to 5 days (or 2-3 days at mid-latitudes). Given these sensor and orbital characteristics, the opportunities for application in precision agriculture are considerable, as these specifications start to meet the needed requirements.

\subsection{Commercial remote sensing opportunities}

In order to maximize the information potential of satellite retrievals for precision agricultural application, an order of magnitude advance in the spatio-temporal resolution is required, relative to that currently available from Landsat type platforms. While not specifically designed for precision agricultural purposes, a number of private companies have launched satellite systems that meet the spatial (and occasionally spectral) requirements ${ }^{19}$. One of the earliest and longest running commercial enterprises is the French initiated Satellite Pour l'Observation de la Terre (SPOT), with the latest SPOT-7 offering $6 \mathrm{~m}$ red, green and blue (RGB) and near-infrared capability. More recently, in 2008 the German based Blackridge AG launched the RapidEye sensor, a constellation of five satellites with a global revisit time of one day (requires tasking of all satellites and using off-nadir pointing capability) and an orthorectified pixel size of $5 \mathrm{~m}$ in five spectral bands (RGB, red-edge and near-infrared). Since then, a number of privately funded start-up companies have entered the earth observation domain. Perhaps the most ambitious of these is Planet (www.planet.com/), a company founded in 2010, but which recently became the largest operator of active space-based satellites (as well as taking ownership of the RapidEye constellation in 2016). The Planet model is based on launching large numbers of so-called "Doves": small nano-satellites that house an RGB - and now a near infrared - camera, that provides 3-5 m ground sampling resolution ${ }^{20}$. The company aims to provide global daily coverage with a constellation of $100+$ doves. Apart from this novel sensing approach, there are other ultra-high resolution $(<1 \mathrm{~m})$ commercial sensors available, including DigitalGlobe's Worldview-3 and related series of satellites (www.digitalglobe.com/), Urthecasts Deimos-1 and -2 satellites (www.urthecast.com) and the EROS B satellite from ImageSat International (http://www.imagesatintl.com/). Unfortunately, while the technical specifications of these commercial sensors are often ideal for precision agricultural applications, the cost of image acquisition is usually prohibitive, limiting their broad scale adoption. As commercial ventures, the satellites often operate on a taskable basis: that is, the user requests in advance for scene retrieval over a specified number of dates, rather than having the option of browsing available image retrospectively. Given the uncertain nature of satellite capture, the timeliness of acquisition may be an issue (i.e. monitoring crop condition over a defined interval of the growing season).

\subsection{Unmanned Aerial Vehicles (UAVs)}

One of the potentially game-changing opportunities in earth observation has come about through advances in the technology associated with unmanned aerial vehicles ${ }^{21}$. Apart from developments in the navigation and flight capabilities of these systems that make them increasingly relevant to both small and large scale precision agricultural applications ${ }^{22}$, there have been parallel advances in the variety of commercial of the shelf (COTS) sensors that can be integrated onto these platforms. These sensor developments have seen a range of potential products that can be used to inform upon crop condition, health and function. Perhaps the most readily available retrieval is optical RGB imagery that can be used not only to visualize crop systems, but also develop higher level products on vegetation height ${ }^{23}$ and biomass ${ }^{24}$. With the addition of advanced thermal and multispectral sensors, the capacity to infer multiple metrics of crop performance can be achieved $^{25}$. However, UAVs are not without their problems and challenges, and much work still needs to be done in translating sensor retrievals into useable and georeferenced products suitable for precision agricultural application. Increases in power supply (i.e. flight times), range, carrying capacity and improved navigation and autonomous operation will see further increases in the uptake of this technology. Figure 1 illustrate two of the most common UAV configurations being used within the Hydrology, Agriculture and Land Observation (HALO) group (hydrology.kaust.edu.sa) here at the King Abdullah University of Science and Technology (KAUST): the quad-copter and fixed wing systems. 

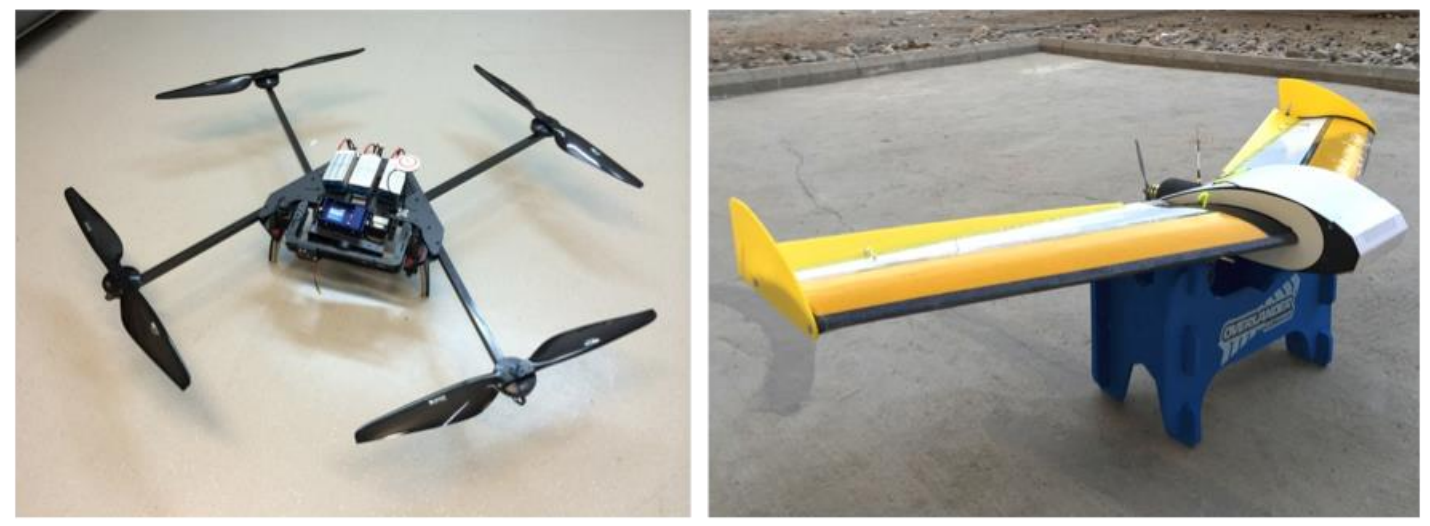

Figure 1. Quadcopter (left) and fixed-wing (right) UAV systems for precision agriculture. Each UAV has approximately $20+$ minutes of flight time, making them suitable for reasonably large area coverage (10-50 Ha.), dependent on flying height.

\section{RETRIEVED VARIABLES FOR PRECISION AGRICULTURE}

\subsection{Determining NDVI for routine crop assessment}

One of the principal techniques in the remote sensing of vegetation is to relate observed spectral reflectance and derived indices to some metric of crop health and condition ${ }^{26,27}$. Foremost amongst the various relationships that have been developed is the Normalised Difference Vegetation Index (NDVI) ${ }^{28}$, a simple difference ratio between reflectance in the red and near-infrared bands, which has been used as a key indicator of crop condition for decades. While the NDVI has recognized limitations ${ }^{29}$, it remains a benchmark in crop assessment, given the immediacy with which it can be retrieved and the simplicity of its interpretation. While many vegetation indices were developed for application with moderate (100 $\mathrm{m}-1 \mathrm{~km})$ to fine resolution $(10 \mathrm{~m}-100 \mathrm{~m})$ satellite sensors in mind, with increasing spatial resolution comes the capacity to move beyond the canopy scale to the actual plant or leaf level. As can be seen in Figure 2, even at resolutions of a few meters, center-pivot tracks along with the detection of considerable within field variability can be discriminated. UAVs add an order of magnitude increase over satellite based retrievals.

Such advances in observational capacity have implications for improving not only the retrieval itself, but also our understanding of the physical relationships between various indices. For instance, the leaf area index (LAI), defined as the one-sided green leaf area per unit horizontal ground area $\left[\mathrm{m}^{-2} \mathrm{~m}^{-2}\right]$, is another common variable used to inform upon the growth and development of crop systems. However, there is an inherent disparity between the in-situ based definition of LAI and that which can be retrieved (or inferred) from remote sensing data ${ }^{30}$. Much of this difference relates to natural systems exhibiting non-random foliage distribution (i.e. vegetation clumping), and accounting for this in radiative transfer models is a non-trivial process. With advances in high-resolution (meter to sub-meter scale) satellite observations and the use of unmanned aerial vehicles comes the capacity to retrieve detailed plant and leaf level information (see Figure 3). How this data can best be used to inform upon crop health and condition remains an area of active research, as the increase in scale may reveal process behavior that requires additional model refinements or improvements in the underlying physical descriptions. As can be seen in Figure 2, the enhanced spatial detail available between satellite platforms offers considerably greater insight into the spatial variability in crop condition, as well as providing important metrics of crop health and performance. 


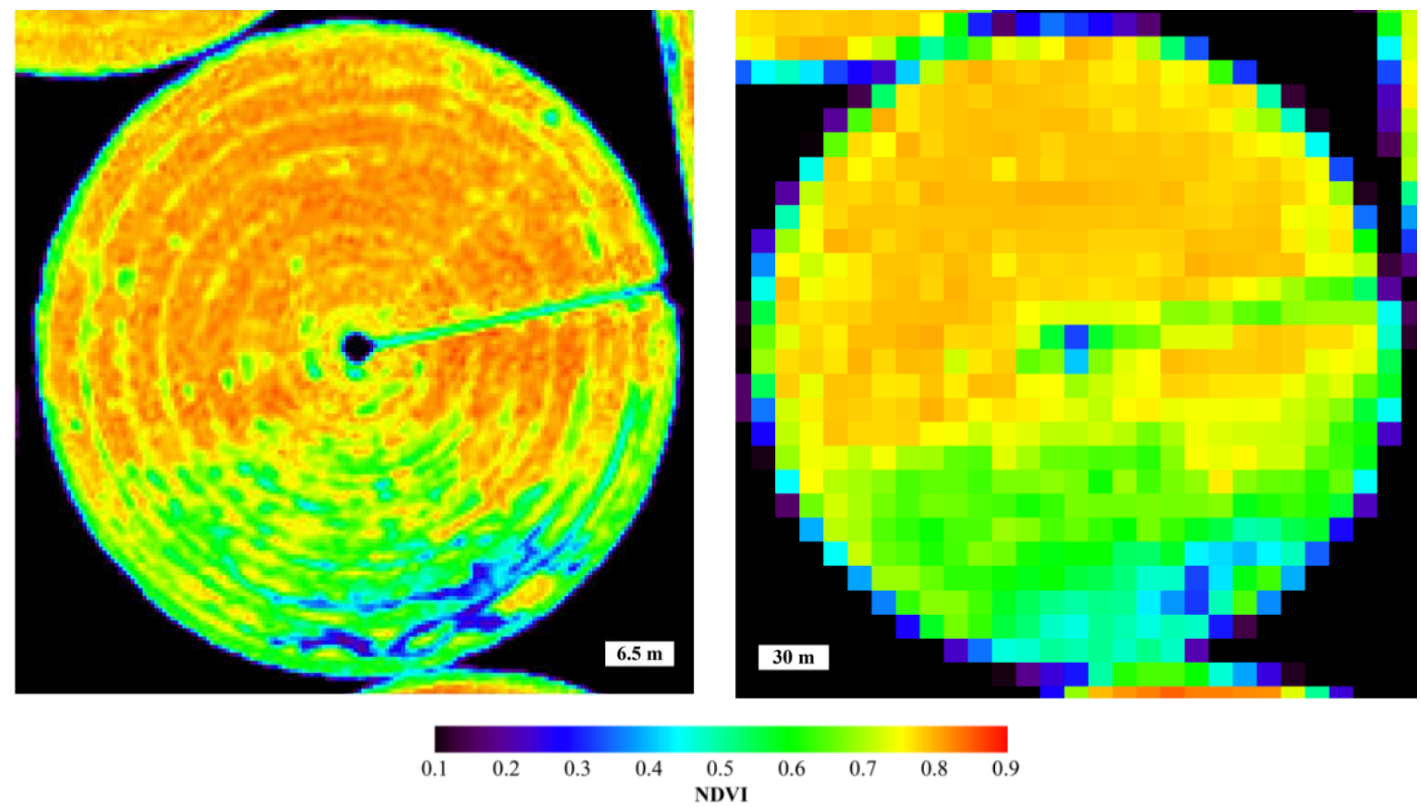

Figure 2. Spatial comparison between satellite imagery from commercial systems such as RapidEye (approx. 6m resolution) and the Landsat satellite (30 m resolution). Imagery were acquired one day apart in October 2015 over a center-pivot field in Saudi Arabia. Values represent the normalized difference vegetation index, as calculated using the REGFLEC model $^{7}$.

\subsection{Retrieval of plant pigment concentrations}

Maps of spatially distributed pigment concentrations (i.e. chlorophyll and carotenoids) can serve as independent measures of plant health and condition, indirectly reflecting spatial variations in nitrogen availability and potential stress. For instance, leaf chlorophyll represents a useful operational proxy for gradual changes in photosynthetic capacity ${ }^{31}$ and lightuse efficiency (LUE) ${ }^{32,33}$, and carotenoid pigment concentrations may reflect changes in LUE on shorter time-scales ${ }^{34,35}$. Bands in the red-edge region of the electromagnetic spectrum have proven informative in estimating leaf chlorophyll content $^{36,37}$, which is of particular interest in precision agriculture applications ${ }^{38}$. Indices based on the reflectance change in the green spectrum ${ }^{39}$ are useful for estimating leaf carotenoids, which are involved in the xanthophyll pigment cycle that changes in response to photosynthetic down-regulation through non-photochemical quenching ${ }^{40}$.

As noted earlier, one of the opportunities in the use of UAVs equipped with VNIR and thermal infrared sensors is exploring vegetation monitoring and stress detection at decimeter scale resolutions: a capacity unavailable from satellite based systems. A combination of physical and statistical methods can be used to exploit the information content contained in green and red-edge bands and bridge visible-to-thermal infrared domains beneficial for the development of meaningful biophysical and biochemical crop products. For instance, a full optical-to-thermal canopy radiative transfer model $(4 \mathrm{SAIL})^{41}$ could be utilized for physical interpretation of the atmospherically corrected VNIR and TIR signals ${ }^{25}$ and translated into maps of leaf area index, leaf chlorophyll and carotenoid. Efforts to explore such an approach have recently been undertaken using a canopy reflectance model inversion approach ${ }^{7}$. Linking 4SAIL with the PROSPECT leaf radiative transfer model ${ }^{42}$ offer the capacity for separate retrieval of leaf chlorophyll and carotenoids pigment that are well informed by the available UAV bands in the red-edge and green portions of the spectrum, respectively.

While canopy radiative transfer models offer a physically based approach for estimating crop features of interest in precision agriculture, statistical machine learning approaches can also be employed ${ }^{43}$. Such frameworks can be used to combine available VNIR and/or TIR bands and indices that inform upon leaf area index and leaf pigments to reproduce target variables. Statistical or machine learning approaches are generally trained on in-situ measured biophysical (leaf area index) and biochemical (leaf pigment) quantities, or can even use variables retrieved from satellite data ${ }^{20}$. While such empirical approaches may lack generality and reproducibility, they can be useful in assessing the robustness and validity of physically based retrievals. Obfuscating effects of soil background, structure, and shadow can be reduced by isolating 
pure vegetation signals from the sub-decimeter UAV reflectance observations: something that is only possible with the high-resolution retrievals available from these platforms.
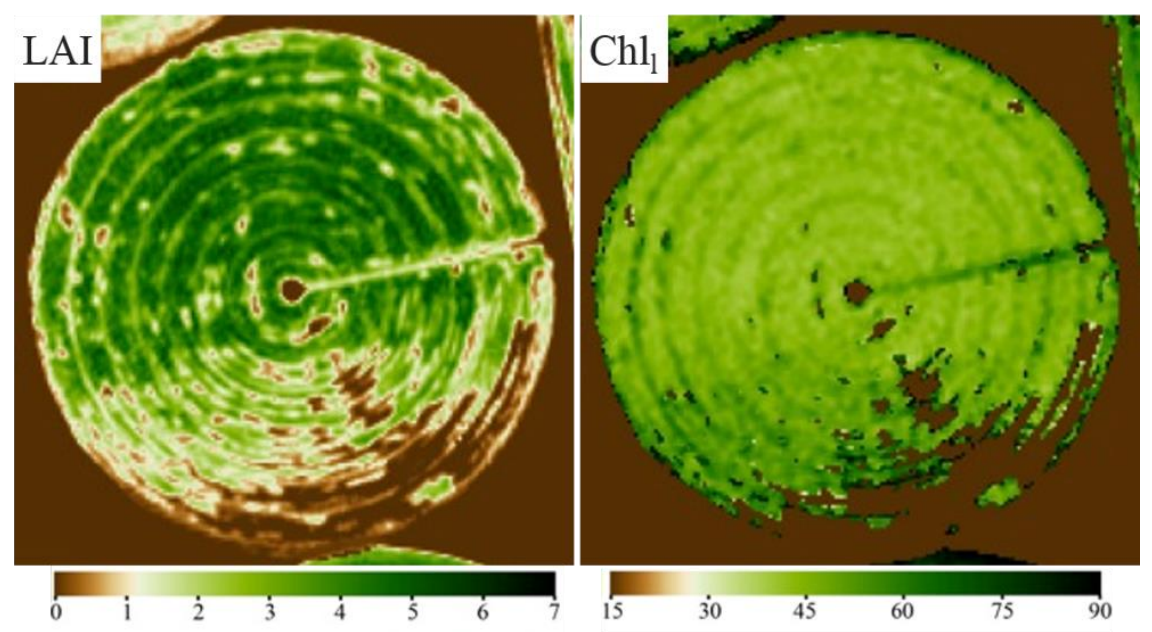

Figure 3. RapidEye derived maps of LAI $\left[\mathrm{m}^{2} \mathrm{~m}^{-2}\right]$ and $\mathrm{Chl}_{l}\left[\mu \mathrm{g} \mathrm{cm}^{-2}\right]$ retrieved over a maize field at the Tawdeehiya farm in Saudi Arabia. Satellite data were collected on May 31, 2015. Dimensions of the center-pivot are approximately $900 \mathrm{~m}$. See [36] for further details on the estimation approach that used red-edge bands to further constrain predictions in REGFLEC.

\subsection{Estimating vegetation height from UAVs}

Crop height plays a key role in regulating canopy and aerodynamic resistances as well as being an important metric for plant health and growth rate. Recent work has shown the sensitivity of surface flux formulations (i.e. evapotranspiration) to crop height and the need for improved estimation of this to increase retrieval accuracy ${ }^{44}$. Using a technique referred to as "structure from motion"45 (SfM), sub-decimeter resolution optical (RGB) UAV data from a SONY-NEX7 20MP digital camera has been used to estimate surface elevations via construction of a 3D point cloud. Although more challenging to retrieve than stationary surface elements such as buildings, as wind effects tend to move vegetation during multi-scene collection, preliminary results along with those from other international groups ${ }^{46}$ illustrate the potential. The retrieval of dynamic crop height from UAVs is an important development in its own right and opens up considerable research lines in forest inventory studies ${ }^{47}$, carbon accounting and crop growth models.
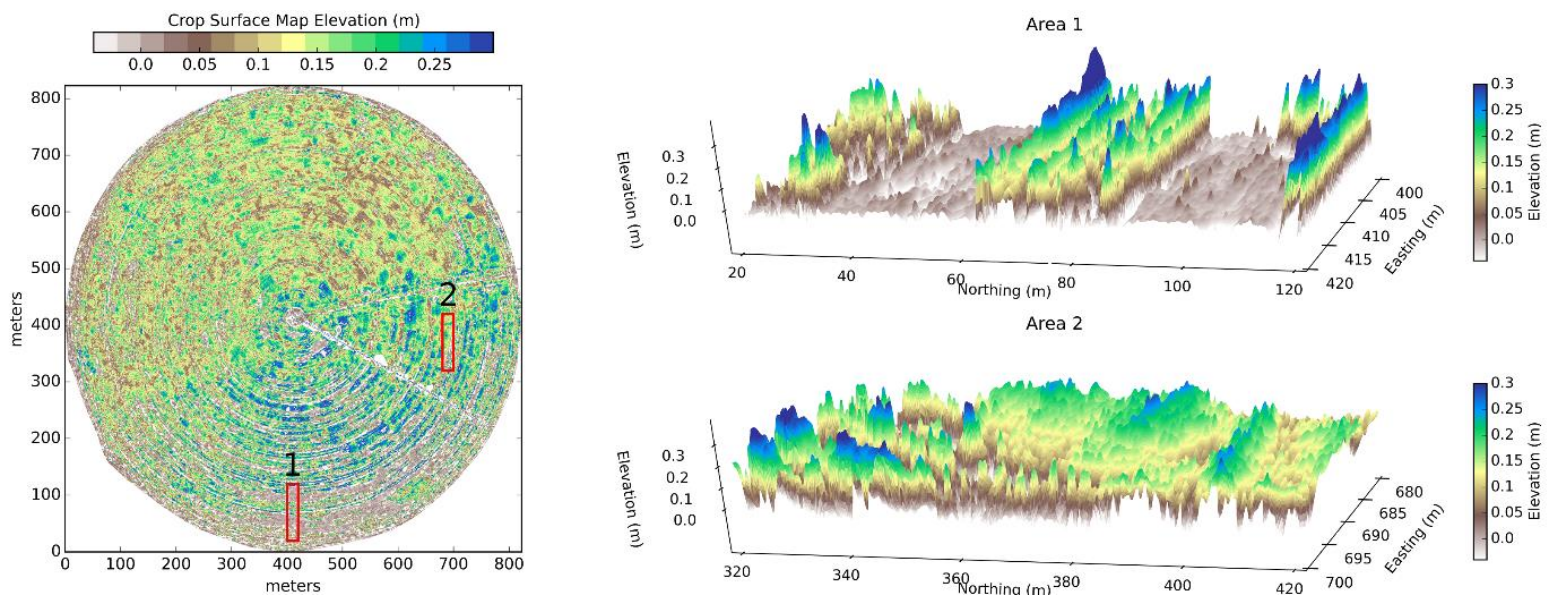

Figure 4. Estimating vegetation height and structure over an alfalfa field using structure from motion approaches. Data were collected using a fixed-wing UAV housing a SONY NEX-7 20MP digital camera on January 27, 2016. Imagery were processed using Pix4D. The center-pivot field is the same as for Figure 3, although having a different crop type. 
As can be seen in Figure 4, the retrieval of digital surface models from UAVs provides considerable insights into the smallscale variability of crop systems that are otherwise not available from current earth observing satellite systems. Clearly defined row-structures in the alfalfa field can be determined in both Sub-Areas 1 and 2, with Area 1 highlighting some crop damaged regions, likely a result of soil or meteorological effects (heavy winds had previously impacted sections of the field). However, there are still some challenges requiring resolution to streamline the production of such data, including accurate (and efficient) geo-referencing approaches, validation of crop height retrievals, examination of the reproducibility of flights as well as the computational constraints involved in processing many millions of points from 3D data clouds.

\subsection{Hydrological modelling based on UAV terrain data}

Digital surface models derived from a UAV SfM workflow can be used for topographic hydrological modelling. Figure 5 shows an example of a $2 \mathrm{~cm}$ resolution orthophoto derived from hundreds of overlapping UAV images acquired from a small fixed-wing UAV with a Sony $\alpha 5100$ APS-C consumer-grade RGB camera. The images were acquired over a bare field in winter in Tasmania, Australia. Through the SfM process a dense point cloud of the bare ground surface was derived, and a digital surface model (DSM) was interpolated at $5 \mathrm{~cm}$ resolution. The DSM was used for subsequent hydrological analysis. The sinks/pits were identified and filled resulting in a depressionless DSM. The drainage direction was derived with the commonly used D8 algorithm, and the flow accumulation was determined for each grid cell. The Topographic Wetness Index (TWI) is defined as follows:

$$
W I=\ln \left(A_{s} / \tan \beta\right)
$$

where $A_{s}$ is the upstream area for a cell and $\beta$ is the slope in degrees. The upstream area was calculated based on the flow accumulation, and the slope was derived from the DSM. The wetness index is very sensitive for errors in the DSM given that a small error in height can significantly change a cell's flow direction. To account for the measurement and interpolation error a Monte Carlo simulation can be applied. This simulation assigns a random error to each grid cell in the DSM and calculates the wetness index based on this permuted layer. This process is repeated 100 times resulting in 100 possible wetness index layers. For each grid cell, the mean of these 100 realizations is taken to represent the final wetness index layer taking into account errors in the input $\mathrm{DSM}^{48}$. The result of the Monte Carlo TWI is shown in Figure 5.
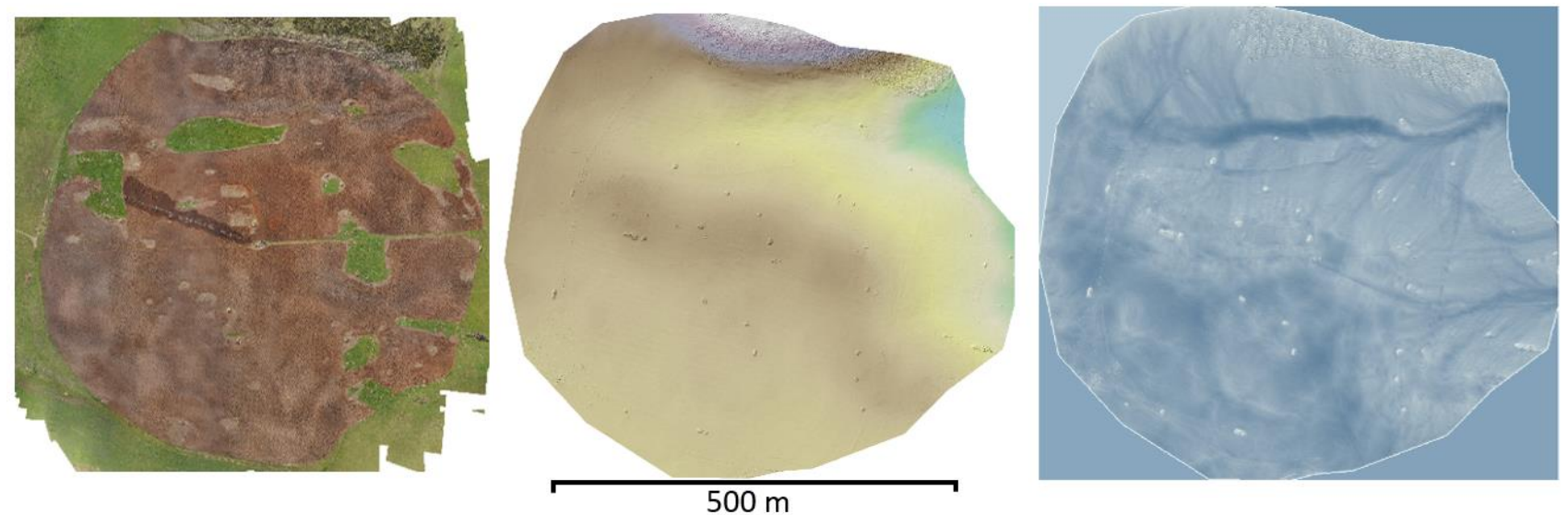

Figure 5. UAV acquired imagery and data of an alkaloid poppy field in Tasmania, Australia. Left: $2 \mathrm{~cm}$ resolution orthophoto derived from a fixed-wing UAV flight of a 70 ha field before the poppy crop was sown; Middle: $5 \mathrm{~cm}$ resolution digital surface model (DSM) derived from the SfM dense point cloud; Right: topographic wetness index (TWI) derived from the DSM's hydrological drainage network.

\section{SUMMARY AND CONCLUSIONS}

Opportunities for the enhanced observation and retrieval of information relevant to precision agriculture abound. With developments in both government and commercial sector based satellite remote sensing, the potential for high-resolution that can be retrieved on a timely basis can now be realized. However, significant challenges remain in the translation of 
remote sensing signals into the needed biochemical, physiological and structural quantities required to characterize crop systems for precision agriculture ${ }^{7,34}$. At the scale of the individual farm, little to no infrastructure exists for the direct assessment of crop water use, health and production. Given the paucity of in-situ data, satellite observations provide the only reasonable approach to infer agricultural response across a range of space and time scales ${ }^{49}$. However, even the best available space-agency based satellite retrievals are limited by both space and time constraints (Fig. 1). Currently, crop water use can only be retrieved at a resolution of approximately $100 \mathrm{~m}$ every 17 days using Landsat 8 data $^{50}$, which is insufficient to resolve the level of within field scale variability required for precision agricultural management. Despite advances in satellite sensor technologies, uptake within the agricultural sector has been limited, due to latency in satellite data processing and delivery, the prohibitive expense of commercial satellites (a single tasked overpass costs several thousand dollars) and a lack of systems for integrating satellite data into useable products for the farmer ${ }^{51}$.

In terms of delivering the level of information required at the field scale, UAVs represent a major opportunity to the field of precision agriculture. With improvements in battery life, automated operation of flight and navigation controls, and a growing range of lightweight sensors for deployment, the reality of near real-time agricultural accounting is far closer than it has ever been before. Yet, as with satellite data, there are still some roadblocks hindering greater uptake at the farmer level. Foremost amongst these is the user involvement required to translate retrievals into georeferenced and calibrated imagery, followed by the translation of these into products of interest to determining crop health and function. However, these are mostly product development challenges rather than technological barriers. As such, it is anticipated that the demand for both UAVs and high-resolution space-based sensor applications will grow rapidly. While legal restrictions on the use of UAVs may provide an obstacle to uptake, the rapid advances in this field illustrate a clear pathway towards improved management of precision agriculture and agricultural activities in general.

\section{REFERENCES}

[1] [The United Nations World Water Development Report 2014: Water and Energy] UNESCO, Paris (2014).

[2] Famiglietti, J. S., "The global groundwater crisis," Nature Clim. Change, 4(11), 945-948 (2014).

[3] Wada, Y., and Bierkens, M. F. P., "Sustainability of global water use: Past reconstruction and future projections," Environmental Research Letters, 9(10), (2014).

[4] Ershadi, A., McCabe, M. F., Evans, J. P., Chaney, N. W., and Wood, E. F., "Multi-site evaluation of terrestrial evaporation models using FLUXNET data," Agricultural and Forest Meteorology, 187, 46-61 (2014).

[5] McCabe, M. F., Wood, E. F., and Gao, H., "Initial soil moisture retrievals from AMSR-E: Multiscale comparison using in situ data and rainfall patterns overs Iowa," Geophysical Research Letters, 32(6), 1-4 (2005).

[6] McCabe, M. F., Kalma, J. D., and Franks, S. W., "Spatial and temporal patterns of land surface fluxes from remotely sensed surface temperatures within an uncertainty modelling framework," Hydrology and Earth System Sciences, 9(5), 467-480 (2005).

[7] Houborg, R., McCabe, M., Cescatti, A., Gao, F., Schull, M., and Gitelson, A., "Joint leaf chlorophyll content and leaf area index retrieval from Landsat data using a regularized model inversion system (REGFLEC)," Remote Sensing of Environment, 159, 203-221 (2015).

[8] Zhao, L., Xiao, H., Zhou, J., Wang, L., Cheng, G., Zhou, M., Yin, L., and McCabe, M. F., "Detailed assessment of isotope ratio infrared spectroscopy and isotope ratio mass spectrometry for the stable isotope analysis of plant and soil waters," Rapid Communications in Mass Spectrometry, 25(20), 3071-3082 (2011).

[9] McCabe, M. F., Ershadi, A., Jimenez, C., Miralles, D. G., Michel, D., and Wood, E. F., "The GEWEX LandFlux project: evaluation of model evaporation using tower-based and globally-gridded forcing data," Geosci. Model Dev. Discuss., 8(8), 6809-6866 (2015).

[10] Stisen, S., McCabe, M. F., Refsgaard, J. C., Lerer, S., and Butts, M. B., "Model parameter analysis using remotely sensed pattern information in a multi-constraint framework," Journal of Hydrology, 409(1-2), 337349 (2011).

[11] Ershadi, A., McCabe, M. F., Evans, J. P., and Walker, J. P., "Effects of spatial aggregation on the multi-scale estimation of evapotranspiration," Remote Sensing of Environment, 131, 51-62 (2013).

[12] McCabe, M. F., Balick, L. K., Theiler, J., Gillespie, A. R., and Mushkin, A., "Linear mixing in thermal infrared temperature retrieval,” International Journal of Remote Sensing, 29(17-18), 5047-5061 (2008). 
[13] Song, C., Woodcock, C. E., Seto, K. C., Lenney, M. P., and Macomber, S. A., "Classification and Change Detection Using Landsat TM Data: When and How to Correct Atmospheric Effects?," Remote Sensing of Environment, 75(2), 230-244 (2001).

[14] Anderson, M. C., Allen, R. G., Morse, A., and Kustas, W. P., "Use of Landsat thermal imagery in monitoring evapotranspiration and managing water resources," Remote Sensing of Environment, 122(0), 50-65 (2012).

[15] Pettorelli, N., Vik, J. O., Mysterud, A., Gaillard, J.-M., Tucker, C. J., and Stenseth, N. C., "Using the satellitederived NDVI to assess ecological responses to environmental change," Trends in Ecology \& Evolution, 20(9), 503-510 (2005).

[16] Irons, J. R., Dwyer, J. L., and Barsi, J. A., "The next Landsat satellite: The Landsat Data Continuity Mission," Remote Sensing of Environment, 122, 11-21 (2012).

[17] Han, W., Yang, Z., Di, L., and Mueller, R., "CropScape: A Web service based application for exploring and disseminating US conterminous geospatial cropland data products for decision support," Computers and Electronics in Agriculture, 84, 111-123 (2012).

[18] Drusch, M., Del Bello, U., Carlier, S., Colin, O., Fernandez, V., Gascon, F., Hoersch, B., Isola, C., Laberinti, P., Martimort, P., Meygret, A., Spoto, F., Sy, O., Marchese, F., and Bargellini, P., "Sentinel-2: ESA's Optical High-Resolution Mission for GMES Operational Services," Remote Sensing of Environment, 120, 25-36 (2012).

[19] Houborg, R., Fisher, J. B., and Skidmore, A. K., "Advances in remote sensing of vegetation function and traits," International Journal of Applied Earth Observation and Geoinformation, 43, 1-6 (2015).

[20] Houborg, R., and McCabe, M. F., "High-resolution NDVI from Planet's constellation of earth observing nanosatellites: a new data source for precision agriculture," Remote Sensing, (in review), (2016).

[21] Anderson, K., and Gaston, K. J., "Lightweight unmanned aerial vehicles will revolutionize spatial ecology," Frontiers in Ecology and the Environment, 11(3), 138-146 (2013).

[22] Zhang, C., and Kovacs, J. M., "The application of small unmanned aerial systems for precision agriculture: a review," Precision Agriculture, 13(6), 693-712 (2012).

[23] Wallace, L., Lucieer, A., Malenovský, Z., Turner, D., and Vopěnka, P., "Assessment of Forest Structure Using Two UAV Techniques: A Comparison of Airborne Laser Scanning and Structure from Motion (SfM) Point Clouds," Forests, 7(3), 62 (2016).

[24] Bendig, J., Bolten, A., Bennertz, S., Broscheit, J., Eichfuss, S., and Bareth, G., "Estimating Biomass of Barley Using Crop Surface Models (CSMs) Derived from UAV-Based RGB Imaging," Remote Sensing, 6(11), 10395 (2014).

[25] Berni, J. A. J., Zarco-Tejada, P. J., Suárez, L., and Fereres, E., "Thermal and narrowband multispectral remote sensing for vegetation monitoring from an unmanned aerial vehicle," IEEE Transactions on Geoscience and Remote Sensing, 47(3), 722-738 (2009).

[26] Bannari, A., Morin, D., Bonn, F., and Huete, A. R., “A review of vegetation indices," Remote Sensing Reviews, 13(1-2), 95-120 (1995).

[27] Dorigo, W. A., Zurita-Milla, R., de Wit, A. J. W., Brazile, J., Singh, R., and Schaepman, M. E., "A review on reflective remote sensing and data assimilation techniques for enhanced agroecosystem modeling," International Journal of Applied Earth Observation and Geoinformation, 9(2), 165-193 (2007).

[28] Tucker, C. J., Pinzon, J. E., Brown, M. E., Slayback, D. A., Pak, E. W., Mahoney, R., Vermote, E. F., and El Saleous, N., "An extended AVHRR 8-km NDVI dataset compatible with MODIS and SPOT vegetation NDVI data," International Journal of Remote Sensing, 26(20), 4485-4498 (2005).

[29] Baret, F., and Guyot, G., "Potentials and limits of vegetation indices for LAI and APAR assessment," Remote Sensing of Environment, 35(2-3), 161-173 (1991).

[30] Gower, S. T., Kucharik, C. J., and Norman, J. M., "Direct and indirect estimation of leaf area index, f(APAR), and net primary production of terrestrial ecosystems," Remote Sensing of Environment, 70(1), 29-51 (1999).

[31] Houborg, R., McCabe, M. F., Cescatti, A., and Gitelson, A., "Leaf chlorophyll constraint on model simulated Gross Primary Productivity in agricultural systems," International Journal of Applied Earth Observation and Geoinformation, 43, 160-176 (2015).

[32] Houborg, R., Anderson, M. C., Daughtry, C. S. T., Kustas, W. P., and Rodell, M., "Using leaf chlorophyll to parameterize light-use-efficiency within a thermal-based carbon, water and energy exchange model," Remote Sensing of Environment, 115(7), 1694-1705 (2011). 
[33] Schull, M. A., Anderson, M. C., Houborg, R., Gitelson, A., and Kustas, W. P., "Thermal-based modeling of coupled carbon, water, and energy fluxes using nominal light use efficiencies constrained by leaf chlorophyll observations," Biogeosciences, 12(5), 1511-1523 (2015).

[34] Homolová, L., Malenovský, Z., Clevers, J. G. P. W., García-Santos, G., and Schaepman, M. E., "Review of optical-based remote sensing for plant trait mapping," Ecological Complexity, 15, 1-16 (2013).

[35] Zarco-Tejada, P. J., Guillén-Climent, M. L., Hernández-Clemente, R., Catalina, A., González, M. R., and Martín, P., "Estimating leaf carotenoid content in vineyards using high resolution hyperspectral imagery acquired from an unmanned aerial vehicle (UAV)," Agricultural and Forest Meteorology, 171-172, 281-294 (2013).

[36] Gitelson, A. A., Viña, A., Masek, J. G., Verma, S. B., and Suyker, A. E., "Synoptic monitoring of gross primary productivity of maize using landsat data," IEEE Geoscience and Remote Sensing Letters, 5(2), 133137 (2008).

[37] Dash, J., and Curran, P. J., "The MERIS terrestrial chlorophyll index," International Journal of Remote Sensing, 25(23), 5403-5413 (2004).

[38] Haboudane, D., Miller, J. R., Tremblay, N., Zarco-Tejada, P. J., and Dextraze, L., "Integrated narrow-band vegetation indices for prediction of crop chlorophyll content for application to precision agriculture," Remote Sensing of Environment, 81(2-3), 416-426 (2002).

[39] Gitelson, A. A., Zur, Y., Chivkunova, O. B., and Merzlyak, M. N., "Assessing carotenoid content in plant leaves with reflectance spectroscopy," Photochemistry and Photobiology, 75(3), 272-281 (2002).

[40] Grace, S. G., and Logan, B. A., "Energy dissipation and radical scavenging by the plant phenylpropanoid pathway," Philosophical Transactions of the Royal Society B: Biological Sciences, 355(1402), 1499-1510 (2000).

[41] Verhoef, W., Jia, L., Xiao, Q., and Su, Z., "Unified optical-thermal four-stream radiative transfer theory for homogeneous vegetation canopies," IEEE Transactions on Geoscience and Remote Sensing, 45(6), 1808-1822 (2007).

[42] Feret, J.-B., François, C., Asner, G. P., Gitelson, A. A., Martin, R. E., Bidel, L. P. R., Ustin, S. L., le Maire, G., and Jacquemoud, S., "PROSPECT-4 and 5: Advances in the leaf optical properties model separating photosynthetic pigments," Remote Sensing of Environment, 112(6), 3030-3043 (2008).

[43] Elarab, M., Ticlavilca, A. M., Torres-Rua, A. F., Maslova, I., and McKee, M., "Estimating chlorophyll with thermal and broadband multispectral high resolution imagery from an unmanned aerial system using relevance vector machines for precision agriculture," International Journal of Applied Earth Observation and Geoinformation, 43, 32-42 (2015).

[44] Ershadi, A., McCabe, M. F., Evans, J. P., and Wood, E. F., "Impact of model structure and parameterization on Penman-Monteith type evaporation models," Journal of Hydrology, 525, 521-535 (2015).

[45] Turner, D., Lucieer, A., and Watson, C., "An automated technique for generating georectified mosaics from ultra-high resolution Unmanned Aerial Vehicle (UAV) imagery, based on Structure from Motion (SFM) point clouds," Remote Sensing, 4(5), 1392-1410 (2012).

[46] Bendig, J., Bolten, A., and Bareth, G., "UAV-based imaging for multi-temporal, very high resolution crop surface models to monitor crop growth variability," Photogrammetrie, Fernerkundung, Geoinformation, 2013(6), 551-562 (2013).

[47] Wallace, L., Lucieer, A., and Watson, C. S., "Evaluating Tree Detection and Segmentation Routines on Very High Resolution UAV LiDAR Data," IEEE Transactions on Geoscience and Remote Sensing, 52(12), 76197628 (2014).

[48] Lucieer, A., Turner, D., King, D. H., and Robinson, S. A., "Using an Unmanned Aerial Vehicle (UAV) to capture micro-topography of Antarctic moss beds," International Journal of Applied Earth Observation and Geoinformation, 27, Part A, 53-62 (2014).

[49] McCabe, M. F., and Wood, E. F., "Scale influences on the remote estimation of evapotranspiration using multiple satellite sensors," Remote Sensing of Environment, 105(4), 271-285 (2006).

[50] Kalma, J. D., McVicar, T. R., and McCabe, M. F., "Estimating land surface evaporation: A review of methods using remotely sensed surface temperature data," Surveys in Geophysics, 29(4-5), 421-469 (2008).

[51] Zhang, C., and Kovacs, J., "The application of small unmanned aerial systems for precision agriculture: a review," Precision Agriculture, 13(6), 693-712 (2012). 